\title{
Does pregabalin improve sleep disorders in fibromyalgia?
}

\section{A pregabalina melhora os distúrbios do sono na fibromialgia?}

\author{
Rodrigo Lorenzi Poluha1, Eduardo Grossmann²
}

DOI 10.5935/2595-0118.20180031

\section{ABSTRACT}

BACKGROUND AND OBJECTIVES: Fibromyalgia is a chronic generalized pain syndrome accompanied by somatic symptoms, mainly represented by sleep disorders. Pregabalin is the main agent among pharmacological treatments.

CONTENTS: An electronic search was performed in the databases Lilacs, Pubmed/Medline, Scielo and ScienceDirect. The keywords used in English and Portuguese were "fibromyalgia"; "sleep disorder", "treatment"; "pregabalin"; "medicine"; "fibromialgia"; "distúrbios do sono", "tratamento"; "pregabalina"; "fármacos". Only articles of literature review, systematic review, meta-analysis and randomized clinical studies published between October 1992 and May 2018 were included.

CONCLUSION: Pregabalin is efficient and safe in the management of sleep disorders in patients with fibromyalgia because it reduces the number of awakenings and increases sleep duration. Keywords: Fibromyalgia, Pregabalin, Sleep wake disorders.

\section{RESUMO}

JUSTIFICATIVA E OBJETIVOS: A fibromialgia é uma síndrome de dor generalizada crônica, acompanhada de sintomas somáticos, representados principalmente por distúrbios do sono. Dentre os tratamentos farmacológicos, a pregabalina é o principal representante.

CONTEÚDO: Foi realizada uma busca eletrônica nas bases de dados Lilacs, Pubmed/Medline, Scielo e ScienceDirect, cruzando-se os seguintes descritores em língua inglesa e portuguesa: "fibromyalgia"; "sleep disorder", "treatment"; "pregabalin"; "medicine"; "fibromialgia"; "distúrbios do sono", "tratamento"; "pregabalina”; "fármacos". Foram incluídos somente artigos de revisão de literatura, revisão sistemática, meta-análise e estudos clínicos randomizados publicados no período de outubro de 1992 a maio de 2018.

\footnotetext{
1. Universidade Estadual de Maringá, Maringá, PR, Brasil.

2. Universidade Federal do Rio Grande do Sul, Porto Alegre, RS, Brasil.

Submitted in April 10, 2018.

Accepted for publication in May 08, 2018.

Conflict of interests: none - Sponsoring sources: none.

Correspondence to:

R. Coronel Corte Real, 513

90630-080, Porto Alegre, RS, Brasil.

E-mail: edugdor@gmail.com

(C) Sociedade Brasileira para o Estudo da Dor
}

CONCLUSÃO: A pregabalina é eficiente e segura no manuseio dos distúrbios do sono em pacientes com fibromialgia, pois diminui o número de despertares e aumenta o tempo de duração do sono.

Descritores: Fibromialgia, Pregabalina, Transtornos do sono-vigília.

\section{INTRODUCTION}

Fibromyalgia (FM) is a syndrome characterized by chronic and generalized pain, with some somatic symptoms such as physical exhaustion, mood disorders, cognition difficulties and sleep disorders ${ }^{1}$. The specialized literature points to levels of prevalence of FM in the general population at between 0.2 and $6.6 \%$; in urban areas, between 0.7 and $11.4 \%$; in rural areas between 0.1 and $5.2 \%$, and in special populations between 0.6 and $15 \%^{2}$. In Brazil, FM is present in up to $2.5 \%$ of the general population and prevails among females, especially among women aged between 35 and $44^{3}$.

FM can affect patients' quality of life and functional capacity more significantly than other inflammatory conditions like rheumatoid arthritis and spondyloarthritis ${ }^{4}$. One single patient with FM can cost tens of thousands of dollars a year, with indirect costs representing the lion's share of total cost, involving loss of productivity, reduction in working hours, absenteeism, invalidity, unemployment, early retirement, informal assistance, and other direct costs ${ }^{5,6}$. Also, patients with FM also have several comorbidities (for example depression, anxiety, and sleep disorders), resulting in an extreme surge in general health-related expenses 5 .

The physiopathology of FM is multifactorial and shows itself in the complexity and variety of the symptoms that patients have experienced $^{7}$. Among the factors involved, we could mention the abnormal function of the autonomic and neuroendocrine systems, genetic influence, and environmental factors that could trigger the condition, like exposure to stress-causing elements ${ }^{8}$. The main physiopathological phenomenon of FM is central sensitization, characterized by the attenuation of the descending pain-inhibiting pathways and the favoring of the ascending pain-creating pathways ${ }^{9}$. These changes help to bring greater sensitivity to pain and persistence of generalized pain ${ }^{8}$. There is also an important change to the structure of sleep, which has an adverse effect on the quality of sleep and also favors a non-reparatory type of sleep ${ }^{10}$. Sleep disorders may be related to fatigue and the reduction of energy. They also may play a part in the intensification of pain ${ }^{8}$, as they can harm the process of healing of damage to muscle tissue, thereby extending the transmission of sensory stimuli from the damaged muscular tissue to the central nervous system (CNS), thereby increasing the perception of muscular pain ${ }^{8,11}$. In turn, the increased pain may also help to intensify sleep disorders, thus maintaining the patient's feeling of fatigue and continuing the process of inadequate reparation of the muscular tissue $e^{8,12}$. 
The treatment of FM must be multimodal due to the heterogeneity of symptoms, and the strategies for treatment must include patient education, together with physiotherapy, psychotherapy, and pharmacotherapy ${ }^{13}$. Among all types of pharmacotherapy, anticonvulsants are the most commonly used, and pregabalin (PG) is the representative of this pharmaceutical class that has been approved for FM in the United States and another 25 countries $^{14}$, thereby being a safe and efficient option ${ }^{15}$, with a satisfactory cost-benefit ratio ${ }^{16}$. With PG, many patients manage to obtain significant benefits regarding pain control, quality of life, and especially in sleep improvement. Moreover, the side effects, even though they are somewhat common, are normally mild and well tolerated in the long term, and may also be monitored in primary care ${ }^{17}$.

Based on the above, a discussion on the relationship between PG and sleep in cases of FM becomes valid, so that the doctor may have the best possible grounding in establishing his or her conduct for the cases considered. Therefore, the purpose of this paper was, through a review of the specialized literature, to answer the question: Does pregabalin improve sleep disorders in cases of fibromyalgia?

\section{CONTENTS}

An electronic search was carried out on the Lilacs, Pubmed/Medline, Scielo, and ScienceDirect databases, crossing the following descriptors in English and Portuguese: "fibromyalgia"; "sleep disorder"; "treatment"; "pregabalin"; "medicine"; "fibromialgia"; "distúrbios do sono"; "tratamento"; "pregabalina"; "fármacos". We only included articles that reviewed the specialized literature or had systematic reviews, meta-analysis or randomized clinical studies, that were published between October 1992 and May 2018.

\section{Sleep in fibromyalgia}

Among patients living with FM, 88\% have reported sleep difficulties in one of the following domains: difficulty in falling asleep; difficulty in staying asleep; or waking up too early, while $63.05 \%$ of the cases have reported difficulties in two or more of these domains ${ }^{18}$. Patients with FM have daily impairment of the performance speed for complex cognitive tasks, together with a diffuse experience of pain and symptoms of non-restoration of sleep, including fatigue, bad mood, and drowsiness ${ }^{19}$. There is an important alteration in the structure of sleep, showing long latency periods at the start of sleep (meaning the time someone takes to fall asleep once the lights are turned off), an increase in stage 1 and reduction in stage 2 , reduction in alpha-delta sleep, and an increase in the number of wakings-up during sleep $p^{10,20,21}$. The shorter duration of sleep stage 2 may predict the levels of pain as experienced in $\mathrm{FM}^{20}$. Sleep deprivation in healthy individuals can cause FM symptoms, including myalgia, sensitivity and fatigue. Moreover, mechanically, the lack of sleep also inhibits the pain-inhibiting descendant pathways, which are important for controlling and tackling pain ${ }^{22}$. The Pittsburgh Sleep Quality Index (PSQI) is a useful way to characterize and quantify sleep disorders in patients with $\mathrm{FM}^{23}$; as a rule, patients with FM show higher PSQI scores when compared to healthy individuals ${ }^{24}$.

\section{Pharmacological characteristics of pregabalin}

$P G$ is an $\alpha_{2} \delta$ ligand which belongs to the class of anticonvulsants, acting through bonding to the $\alpha_{2}-\delta$ subunit of the voltage-dependent pre-syn- aptic calcium channels, which results in a slower flow of calcium through the channels, possibly through interruption of transport and/or through the reduction of the flow of calcium towards the interior of the cell125. Later on, this reduced flow of calcium inhibits the pre-synaptic release of neurotransmitters, including glutamate and $\mathrm{P}$ substance, which are involved in the abnormal processing of pain, as seen in the patient living with $\mathrm{FM}^{26}$. PG can be administered on an empty stomach or together with food, without this having any significant clinical effects upon the degree of absorption thereof. The plasmatic concentrations reach a peak within 1 to 2.5 hours after the drug is applied, both for single and multiple doses ${ }^{25}$. Metabolization in humans is almost insignificant, given that approximately $98 \%$ of PG is excreted unchanged in the urine $e^{27}$. There is no need to monitor the routine concentrations of $\mathrm{PG}^{27}$. Due to the lack of bonding to the proteins and the negligible metabolism in the liver, PG may be safely combined with other pharmaceutical products and used in patients with kidney failure, when the dose is appropriate; in this case, withdrawal of the drug must be a gradual process ${ }^{28}$. Sedation, dizziness, peripheral edema, and xerostomia (dry mouth) are the most common adverse effects ${ }^{29}$.

\section{Pregabalin in sleep disturbances in cases of fibromyalgia}

The efficiency and security of PG as monotherapy in the treatment of patients with FM is well documented. A data analysis involving polysomnography was conducted on a cross-sectional, randomized and placebo-controlled study, investigating the effects of this pharmaceutical product and placebo, on sleep patterns in cases of FM. A total of 119 patients [103 (87\%) women] were randomized (1:1) for PG (150 to $450 \mathrm{mg} /$ day) or placebo, during treatment period 1 , and vice-versa for treatment period 2. There was a period of transition lasting two weeks, between the completion of period 1 and the start of period 2. The target dose of PG was between 300 and $450 \mathrm{mg} /$ day. PG, when compared to the placebo, reduced the number of awakenings during sleep, and increased the duration of sleep, with these effects being reflected and correlated with a reduction of "light sleep" (stage 1) and an increase in "deep sleep! (slow-wave sleep). More specifically, treatment with PG did not have an important effect in bringing about sleep, whether at the start of during the night, when sleep was resumed. On the contrary, treatment with PG resulted in a consolidation of sleep, by reducing the number of times someone woke up during sleep (that means leading to fewer alternations between sleep and awareness) and, in so doing, increased the duration of sleep, thereby reducing the fragmentation thereo $f^{30}$. Clinically, the beneficial effects of PG on sleep in patients living with FM are also shown by several different academic papers. A randomized and double-blind study, controlled with the use of a placebo, made use of PG $(300 \mathrm{mg}$, $450 \mathrm{mg}$ and $600 \mathrm{mg} /$ day) or a placebo, in adult patients with FM, for a total of 12 weeks. The sample had a total of 748 patients (with typical ages between 48 and 60, and who had FM for 9 to 10 years), and these were randomized into four groups. PG led to significant improvement in the quality of sleep, as also in the initiation and maintenance of sleep, as well as bringing down the rate of disturbances and occurrence of sleep-related problems. All doses showed significant improvements when compared with the placebo. However, the effects of the treatment were more significant for the groups of $450 \mathrm{mg}$ and $600 \mathrm{mg}$, with regard to the daily scores of quality and sleep problems, respectively. Mediation 
models showed that $43-80 \%$ of benefits regarding sleep (compared with the placebo) were direct effects of the PG, with the rest being the result of an indirect effect of the treatment, through pain relief ${ }^{1}$. Initial pain could be an important factor influencing the results of treatment with PG. Five clinical trials, randomized, double-blind, placebo-controlled made use of PG (at doses between 300 and $450 \mathrm{mg}$ / day) in patients with FM and who experienced moderate to intense initial pain. Individuals aged $\geq 18$ years had average scores of initial pain, on a zero to ten scale $(\geq 4$ and $<7)$ or intense pain $(\geq 7$ and $\leq 10)$, without any difference being observed between the treatment groups. PG was efficient for 12 weeks, in reducing pain and improving quality of sleep among patients with FM and moderate to intense pain at the start of treatment, with a greater effect being observed among the subgroup with intense initial pain ${ }^{32}$. These results are confirmed by another randomized, double-blind, placebo-controlled study with the same posology [PG (300 mg/day, $450 \mathrm{mg} /$ day and $600 \mathrm{mg} /$ day) or placebo, given twice a day]. However, the treatment period was of 14 weeks, in a population of 750 patients with FM, selected at random, and placed in one of the four posology groups. The data shows that, when compared with the placebo, all three doses of PG showed a significant improvement in the scores for intensity of pain and quality of sleep ${ }^{33}$.

The time for the effects of PG on cases of FM to be felt was also studied. A total of 2,747 patients with FM (aged between 18 and 82) were included in an analysis involving four trials of 8 to 14 weeks duration, placebo-controlled, with PG at a fixed dose (150 to $600 \mathrm{mg} /$ day), to establish the time for immediate and sustained clinical improvement in intensity of pain and quality of sleep. In the treatments with PG, there were significant improvements to pain and sleep patterns, at the end of the study, when compared to the placebo, with the immediate responses occurring between 1 and 2 weeks after the start of treatment. The time elapsed up until the start of clinical improvement, based on the quality of sleep, was also calculated. At least $25 \%$ of the patients who received PG obtained a sustained clinical improvement on the $2^{\text {nd }}$ day, compared with the $9^{\text {th }}$ day in the case of those who received a placebo, and at least $50 \%$ of those who received PG showed a sustained improvement to sleep on the $11^{\text {th }}$ day. The value of the $50^{\text {th }}$ percentile cannot be calculated for the placebo group, as at no moment did $50 \%$ of the placebo-treated patients show a sustained clinical improvement to sleep patterns. The authors thus concluded that both the immediate and sustained clinical improvements in sleep quality and intensity of pain occurred more quickly among the patients using PG when compared to the placebo group ${ }^{34}$.

Even though most studies on PM are mainly concentrated on the treatment with monotherapy, PG can also be safely combined with other pharmaceuticals and may make the sedation more serious when combined with depressants of the central nervous system ${ }^{28}$. A study compared a combination of PG-duloxetine to each monotherapy. Using a crossed delineation, randomized and double-blind, in 4 periods, patients with FM received the maximum tolerated placebo dose, PG (450mg), duloxetine $(120 \mathrm{mg})$ and a combination of pregabalin and duloxetine, for 6 weeks. At the end of the appraisal period, the pharmacological combination outperformed the placebo and the monotherapies, in a multitude of different results, mainly the improvement in pain and the quality of sleep ${ }^{35}$. One study compared the combination of PG with trazodone (an antidepressant) versus trazodone-based monotherapy. Trazodone was administered ( 50 to $300 \mathrm{mg} /$ day) to 66 patients with FM, for 12 weeks. Next, 41 of these patients also received an addition of PG ( 75 to $450 \mathrm{mg} /$ day) to the treatment, for 12 weeks. Even though the monotherapy was able to promote benefits related to the reduction of pain and improvement of sleep, the pharmacological combination gave even better results, both regarding the reduction of pain and improvement of sleep patterns $s^{36}$.

Since patients with FM often show comorbidities, in some cases, the treatment of FM shall be together with the treatment of any other conditions ${ }^{5}$. In order to appraise the efficiency and security of PG in patients with FM and comorbid depression, taking antidepressant drugs at the same time, a crossed study, randomized and double-blind, with 2 periods and 2 subgroups, placebo-controlled, consisted of two periods of treatment for 6 weeks, separated by a two-week washout period. Patients with FM and aged $\geq 18$ years old, taking a stable dose of a selective serotonin recapture inhibitor, or an inhibitor of serotonin/norepinephrine for depression, were randomized, at a proportion of $1: 1$, to receive PG/Placebo or placebo/PG, at 300 or $450 \mathrm{mg} /$ day. The antidepressant was continued throughout the study. When compared to the placebo, the average final scores for pain intensity had a statistically significant reduction in the use of PG. Also, there was an important improvement regarding anxiety, depression, and particularly of sleep quality. The authors thus reached the conclusion that PG can be given together with antidepressants, without in any way affecting the treatment of the depressive syndrome and also helping to improve both situations ${ }^{37}$. Even though the indicated dose of PG for effects on sleep in cases of FM is 300 or $450 \mathrm{mg}$ divided into two applications a day, we recommend a gradual increase based on weekly increments, based on the tolerability of adverse effects and the therapeutical response ${ }^{28}$. PG shows a good profile regarding the safety of adverse effects and tolerability of patients with FM, in long-term monitoring $(14,26 \text { or } 52 \text { weeks })^{38,33}$.

PG is available as $50,75,100,150,200,225$, and $300 \mathrm{mg}$ tablets. Average daily dosing ranges from 50 to $600 \mathrm{mg} /$ day. This variability may facilitate the titration in fibromyalgia treatment in addition to making its maintenance more flexible, adjusting the dosage to each patient ${ }^{28,38,40-43}$.

\section{CONCLUSION}

PG is a safe and efficient drug when dealing with sleep disorders in patients with FM due to the reduction in the number of awakenings and increases in the duration of sleep.

\section{REFERENCES}

1. Häuser W, Ablin J, Fitzcharles MA, Littlejohn G, Luciano JV, Usui C, et al. Fibromyalgia. Nat Rev Dis Primers. 2015;1:15022.

2. Marques AP, Espírito Santo AS, Berssaneti AA, Matsutani LA, Yuan SLK. A prevalência de fibromialgia: atualização da revisão de literatura. Rev Bras Reumatol. 2017;57(4):356-63.

3. Heymanna RE, Paiva ES, Martineza JE, Helfenstein Jr M, Rezende MC, Provenza JR, et al. Novas diretrizes para o diagnóstico da fibromialgia. Rev Bras Reumatol. 2017;57(2):S467-76

4. Ovayolu N, Ovayolu O, Karadag G. Health-related quality of life in ankylosing spondylitis, fibromyalgia syndrome, and rheumatoid arthritis: a comparison with a selected sample of healthy individuals. Clin Rheumatol. 2011;30(5):655-64.

5. Skaer TL. Fibromyalgia: disease synopsis, medication cost effectiveness and economic burden. Pharmacoeconomics. 2014;32(5):457-66.

6. Silverman S, Dukes EM, Johnston SS, Brandenburg NA, Sadosky A, Huse DM. The economic burden of fibromyalgia: comparative analysis with rheumatoid arthritis. 
Curr Med Res Opin. 2009;25(4):829-40.

7. Clauw DJ. Fibromyalgia: a clinical review. JAMA. 2014;311(15):1547-55.

8. Bradley LA. Pathophysiology of fibromyalgia. Am J Med. 2009;122(12 Suppl):S22-30.

9. Chakr RM, Xavier RM. Fibromialgia: princípios práticos que auxiliam na indicação e no ajuste do tratamento medicamentoso. J Bras Med. 2014;102(6):23-9.

10. Harding SM. Sleep in fibromyalgia patients: subjective and objective findings. Am J Med Sci. 1998;315(6):367-76.

11. Bennett RM, Clark SR, Campbell SM, Burckhardt CS. Low levels of somatomedin C in patients with the fibromyalgia syndrome. A possible link between sleep and muscle pain. Arthritis Rheum. 1992;35(1):1113-6.

12. Davies KA, Macfarlane GJ, Nicholl BI, Dickens C, Morriss R, Ray D, et al. Restorative sleep predicts the resolution of chronic widespread pain: results from the EPIFUND study. Rheumatology. 2008;47(1):1809-13.

13. Macfarlane GJ, Kronisch C, Dean LE, Atzeni F, Häuser W, Fluß E, et al. EULAR revised recommendations for the management of fibromyalgia. Ann Rheum Dis. 2017;76(2):318-28.

14. Üçeyler N, Sommer C, Walitt B, Häuser W. WITHDRAWN: anticonvulsants for fibromyalgia. Cochrane Database Syst Rev. 2017;(10):CD010782.

15. Moore RA, Straube S, Wiffen PJ, Derry S, McQuay HJ. Pregabalin for acute and chronic pain in adults. Cochrane Database Syst Rev. 2009;(3):CD007076.

16. Lloyd A, Boomershine CS, Choy EH, Chandran A, Zlateva G. The cost-effectiveness of pregabalin in the treatment of fibromyalgia: US perspective. J Med Econ. 2012;15(3):481-92.

17. Bhusal S, Diomampo S, Magrey MN. Clinical utility, safety, and efficacy of pregabalin in the treatment of fibromyalgia. Drug Healthc Patient Saf. 2016;17(8):13-23.

18. Bigatti SM, Hernandez AM, Cronan TA, Rand KL. Sleep disturbances in fibromyalgia syndrome: relationship to pain and depression. Arthritis Rheum. 2008; 59(7):961-7.

19. C-oté KA, Moldofsky H. Sleep, daytime symptoms, and cognitive performance in patients with fibromyalgia. J Rheumatol. 1997;24(10):2014-23.

20. Burns JW, Crofford LJ, Chervin RD. Sleep stage dynamics in fibromyalgia patients and controls. Sleep Med. 2008;9(6):689-96.

21. Diaz-Piedra C, Catena A, Sánchez AI, Miró E, Martínez MP, Buela-Casal G. Sleep disturbances in fibromyalgia syndrome: the role of clinical and polysomnographic variables explaining poor sleep quality in patients. Sleep Med. 2015;16(8):917-25.

22. Choy EH. The role of sleep in pain and fibromyalgia. Nat Rev Rheumatol. 2015;11(9):513-20

23. Osorio CD, Gallinaro AL, Lorenzi-Filho G, Lage LV. Sleep quality in patients with fibromyalgia using the Pittsburgh Sleep Quality Index. J Rheumatol. 2006;33(9):1863-5.

24. Rener-Sitar K, John MT, Pusalavidyasagar SS, Bandyopadhyay D, Schiffman EL. Sleep quality in temporomandibular disorder cases. Sleep Med. 2016;25:105-12.

25. Ben-Menachem E. Pregabalin pharmacology and its relevance to clinical practice. Epilepsia. 2004; $45(6): 13-8$

26. Kim L, Lipton S, Deodhar A. Pregabalin for fibromyalgia: some relief but no cure. Cleve Clin J Med. 2009;76(1):255-61.

27. Schulze-Bonhage A. Pharmacokinetic and pharmacodynamic profile of pregabalin and its role in the treatment of epilepsy. Expert Opin Drug Metab Toxicol.
2013;9(1):105-15.

28. Boomershine CS. Pregabalin for the management of fibromyalgia syndrome. J Pain Res. 2010;3:81-8.

29. Toth C. Drug safety evaluation of pregabalin. Expert Opin Drug Saf. 2012;11(3):487-502.

30. Roth T, Bhadra-Brown P, Pitman VW, Resnick EM. Pregabalin improves fibromyalgia-related sleep disturbance. Clin J Pain. 2016;32(4):308-12.

31. Russell IJ, Crofford LJ, Leon T, Cappelleri JC, Bushmakin AG, Whalen E, et al The effects of pregabalin on sleep disturbance symptoms among individuals with fibromyalgia syndrome. Sleep Med. 2009;10(6):604-10.

32. Clair A, Emir B. The safety and efficacy of pregabalin for treating subjects with fibromyalgia and moderate or severe baseline widespread pain. Curr Med Res Opin. 2016;32;(3):601-9.

33. Arnold LM, Russell IJ, Diri EW, Duan WR, Young JP Jr, Sharma U, et al. A 14-week, randomized, double-blinded, placebo-controlled monotherapy trial of pregabalin in patients with fibromyalgia. J Pain. 2008;9(9):792-805.

34. Arnold LM, Emir B, Pauer L, Resnick M, Clair A. Time to improvement of pain and sleep quality in clinical trials of pregabalin for the treatment of fibromyalgia. Pain Med. 2015;16(1):176-85.

35. Gilron I, Chaparro LE, Tu D, Holden RR, Milev R, Towheed T, et al. Combination of pregabalin with duloxetine for fibromyalgia: a randomized controlled trial. Pain. 2016;157(7):1532-40.

36. Calandre EP, Morillas-Arques P, Molina-Barea R, Rodriguez-Lopez CM, Rico-Villademoros F. Trazodone plus pregabalin combination in the treatment of fibromyalgia: a two-phase, 24-week, open-label uncontrolled study. BMC Musculoskelet Disord. 2011;12(16):1-9.

37. Arnold LM, Sarzi-Puttini P, Arsenault P, Khan T, Bhadra Brown P, Clair A, et al. Efficacy and safety of pregabalin in patients with fibromyalgia and comorbid depression taking concurrent antidepressant medication: a randomized, placebo-controlled study. J Rheumatol. 2015;42(7):1237-44.

38. Derry S, Cording M, Wiffen PJ, Law S, Phillips T, Moore RA. Pregabalin for pain in fibromyalgia in adults. Cochrane Database Syst Rev. 2016;(9):CD011790.

39. Arnold LM, Emir B, Murphy TK, Zeiher BG, Pauer L, Scott G, et al. Safety profile and tolerability of up to 1 year of pregabalin treatment in 3 open-label extension studies in patients with fibromyalgia. Clin Ther. 2012;34(5):1092-102.

40. Baidya DK, Agarwal A, Khanna P, Arora MK. Pregabalin in acute and chronic pain. J Anaesthesiol Clin Pharmacol. 2011;27(3):307-14.

41. Viñas-Bastart M, Oms-Arias M, Pedraza-Gutiérrez À, Lizano-Díez I, Modamio P, Mariño EL. Clinical use of pregabalin in general practice in Catalonia, Spain: a population-based cross-sectional study. Pain Med. 2017;17. Epub ahead of print.

42. Straube S, Derry S, Moore RA, Paine J, McQuay HJ. Pregabalin in fibromyalgia--responder analysis from individual patient data. BMC Musculoskelet Disord. 2010;11:150-8.

43. Tzellos TG, Toulis KA, Goulis DG, Papazisis G, Zampeli VA, Vakfari A, Kouvelas D. Gabapentin and pregabalin in the treatment of fibromyalgia: a systematic review and a meta-analysis. J Clin Pharm Ther. 2010;35(6):639-56. 